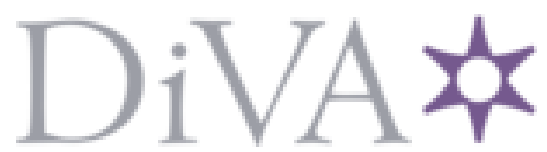

http://www.diva-portal.org

This is the published version of a paper published in Journalism - Theory, Practice \& Criticism.

Citation for the original published paper (version of record):

Bengtsson, S., Johansson, S. (2021)

A phenomenology of news: Understanding news in digital culture

Journalism - Theory, Practice \& Criticism, 22(11): 2873-2889

https://doi.org/10.1177/1464884919901194

Access to the published version may require subscription.

N.B. When citing this work, cite the original published paper.

Permanent link to this version:

http://urn.kb.se/resolve?urn=urn:nbn:se:sh:diva-40081 


\title{
A phenomenology of news: Understanding news in digital culture
}

\section{Stina Bengtsson $(\mathbb{D}$ and Sofia Johansson}

Södertörn University, Sweden

\begin{abstract}
Digital media transform news. First, we see this in changing use patterns. Young people today show a decline in interest in traditional news formats and practices, such as watching the evening news on TV or reading a daily newspaper. But digital media also transform production and distribution of news, leading to new ways to conceptualise and understand news. In the light of these profound transformations in audience behaviour many have started to question the concept of news in news research. In the light of such altered production and distribution contexts which are likely to fundamentally impact on audiences' definitions and perceptions, this article sets out to explore alternative ways to understand and conceptualise news, beyond traditional news research. What is news today, and how can we study it from the perspective of news audiences, without resorting to preconceived notions? We propose a theoretical approach based in classic phenomenology which, we argue, will open up for further reconsideration of the concept as well as providing a potentially fruitful basis for research on digital news consumption. Phenomenology takes human existence as its vantage point and explores how human subjects exist and create meaning in their everyday lives in relation to basic categories such as time, space and (sociocultural) relevance. We argue phenomenology to be particularly relevant for exploring new meanings of news as the basic dimensions of phenomenology not only coincide with the basic dimensions of news consumption, but also of those of news values; time, space, and (sociocultural) relevance.
\end{abstract}

\section{Keywords}

Audiences, everyday life, method, news, phenomenology

\section{Corresponding author:}

Stina Bengtsson, Media and Communication Studies, Södertörn University, 14I 89 Huddinge, Sweden.

Email: stina.bengtsson@sh.se 


\section{Introduction}

'Little is known about what the news users now have come to see as news'

(Swart et al., 2016: 8)

News, for a long time considered a distinct commodity produced by journalists and established media organisations, is currently often considered a concept 'in flux'. This is prompted by well-documented changes in news production, including altering practices of journalists and the opportunities for media users to produce and share content, as well as changes in news distribution, where social media platforms, not least, have impacted on the flow of advertising revenue as well as leading to an algorithmically governed news dissemination. Alongside, transformations in the production and distribution of news have followed novel ways to consume news, with changing use patterns a muchdiscussed topic in scholarly debates about journalism and democracy.

It is arguable that the altered context for news consumption interlinks not only with news consumption patterns, but also with more varied understandings of the concept itself. Today, a wide variety of online news sites, apps and social media compete for the attention of audiences, with social networking sites such as Facebook, Instagram or Russian VKontakte developing into prominent news platforms, especially for young adults (c.f. Simons, 2016). Young people across the world show a decline in interest in traditional news formats (e.g. Franklin et al., 2009; Opermann, 2014; Papathanassopoulos et al., 2013; Thurman, 2019), whereas a micro-blog such as Twitter can function as an important source of information for traditional media (Broersma and Graham, 2013) but also as a mass news medium in itself (Hermida, 2010). Similarly, personalised news feeds on SNSs, based on a mixture of personal posts, shared content, photos, films, videos and adverts, are defined within the sites as 'news', making rigid distinctions between 'news media' and 'social media' problematic.

Indeed, in the light of the profound transformations in audience behaviour, many have started to question the concept of news in news research. Chris Peters (2012) has pointed out that

(...) all too often scholars rely on a traditional twentieth century notion of professional journalism to understand shifting audience conceptions of what news 'is'. (p. 699).

In line with such emphasis, this article sets out to explore alternative ways to understand and conceptualise news. What is news today, and how can we study the phenomenon from the perspective of news audiences, without resorting to preconceived notions? Using a newly started research project on news understanding among young adults in Estonia, Russia and Sweden as a backdrop to discuss such questions, we propose a theoretical approach based in phenomenology, to open up for further reconsideration of the concept.

In the following, we expand on scholarly arguments for rethinking news, and summarise prominent strands in existing research on digital news consumption in everyday life. We then continue by discussing phenomenology as a framework for extending such 
research to encompass broadening notions of news and conclude by condensing the discussion into a basic model for analysis, and suggest ways of implementing phenomenological perspectives in empirical research. The article, overall, aims to make a contribution to ongoing debates about news consumption - by highlighting conceptual change and advancing the present research agenda.

\section{Rethinking news}

A long-established definition of news is as a commodity produced and packaged within organised journalistic institutions - involving, among other things, an emphasis on newness, a truth-claim, a specific tone and a set of particular values and actors determining what is newsworthy to an audience (e.g. Galtung and Ruge, 1965; Gans, 1979; Tuchman, 1978). With some variation, this is also the way the concept is commonly used in news research, even though it might be classified into sub-categories such as, for instance, 'local' and 'national', or 'hard' and 'soft' news (c.f. Reinemann et al., 2012).

But as argued earlier, news and, indeed, journalism more broadly, is no longer what it used to be - if it ever was (c.f. Maxwell Hamilton and Tworek, 2017). Deuze and Witschge (2020) have argued that journalism is transitioning from a coherent industry to a highly varied and diverse range of practices, which is a reason to look 'beyond' journalism, and theorise it from the ground up - openly focussing on where, how, by whom and why, without being constrained by old preconceptions about its nature. From a similar standpoint, Peters (2012) call for scholars to look beyond professional journalism when addressing how audiences have come to understand news today, equally opens up for more varied conceptualisations stemming from audience research (also Peters and Schrøder, 2018).

Yet, although developments within the contemporary digital media landscape have clearly contributed to a lively scholarly discussion regarding the current features and functions of news - it is possible to also situate a rethinking within historical and comparative perspectives. Maxwell Hamilton and Tworek (2017) argue that we must acknowledge not only the current changes in news consumption practices, but also the larger historical misconceptions in news and journalism research regarding what news, seen from a broader temporal and spatial angle, is and can be. They claim the 'angloamerican model' of journalism (that has heavily dominated news research) is only one way of understanding news, one that easily gets challenged both by historic perspectives and current news consumption patterns, as well as by a global outlook. Disentangling the concept of news, they underline that

news is about more than journalism and existed before professional reporters and editors, before the idea of fairness and objectivity, before newspapers. (p. 392)

There have been 'many ways of disseminating news throughout history' they mean, 'from songs to jokes, to today's multi platform media' (p. 392). ${ }^{1}$ Such a broad sociocultural perspective of news, furthermore, reveals that

people have always cared about news. They have just found different modes to gather and consume that news. The newspaper took several centuries to become the most popular mode of 
disseminating news from its emergence in the 17th century to its dominance in the 19th and 20th centuries (Pettegree, 2014). People gossiped about news, they sang songs, and they speared rumours. In pre-revolutionary Paris they gathered under a tree (. . .) to swap stories about the French elites. (Pettegree, 2014: 402)

Maxwell Hamilton and Tworek conceptualise such transformations as 'epigenetic changes' which converts the essence of what journalism and news are, changes which are necessary to acknowledge when aiming for a nuanced understanding of what a piece of news can be today. Such changes, however, are not to be seen as new as, they mean, claiming, 'This is not a break in the history of news, it is a continuation of it' (p. 403).

So, if (journalism and) news are (constantly) changing, how do we get a grip of them, and what do contemporary media transformations mean to the notion of news? A useful starting point for such enquiry is no doubt to examine audiences' own perceptions and ideas of news, which is also an approach suggested by several scholars who argue for a rethinking of previous ways of categorising news. Peters (2012) has argued for a focus upon news practices in their cultural context, as "if we want to understand the meaning audiences make from news, studies of content must be augmented by a focus on "flow" (the conversation and uses of news by audiences)' (p. 702), Swart et al. (2016) in a conceptual discussion about public connection, similarly argue for paying attention to the way news is currently embedded within people's everyday lives (p. 3).

Debates about the meaning of news within the digital media landscape, then, have recently underlined a need for renewed study of news audiences, in order to examine how news is defined and understood as part of everyday life. Such enquiry has potential to add a perspective to research on digital news consumption, which has often started from conventional notions of news.

\section{Digital news in everyday life}

Research about digital news consumption has revolved primarily around citizens' political knowledge, civic engagement and democracy (see Boczkowski and Mitchelstein, 2013; Mitchelstein and Boczkowski, 2010: 1088-1090; Prior, 2007), ${ }^{2}$ including how citizens' understand disinformation, and algorithmic control over news habits (Balmas, 2014; DeVito, 2016; Khaldarova and Pantti, 2016; Marchi, 2012). This includes discussions about audiences' participation and collaboration (e.g. Almgren and Olsson, 2016; Bergström, 2008; Jönsson and Örnebring, 2011); and how users turn into content producers and distributors - including affirmative perspectives as well as more critical ones. ${ }^{3}$

A less developed area of study examines the way digital news interweaves with audiences' everyday lives, and how sense-making practices around news are situated socially, culturally and experientially. This research, interlinking with the wider field of audience studies in media research, approaches news consumption from a qualitative, 'bottom up', perspective, stressing the significance of studying the use and understanding of media content and technologies in everyday contexts (see Madianou, 2013). Such work has previously underlined the relations between news and notions of routine, time and space (Bausinger, 1984); the social and family contexts (e.g. Hagen, 1992; Lull, 1990; Morley, 
1980); social identity (Gauntlett and Hill, 1999); how news gains meaning as story-telling, relating to forms of folk culture (Bird, 1992, 2000, 2011) and play a role in audience communities (Johansson, 2007; Wasserman, 2010). This research orientation has highlighted news as meaningful beyond its political function, while also emphasising everyday life as a formative site for communicative experiences and identities drawn on for more overt expressions of civic engagement.

Recent studies examining digital news use have emphasised multi-platform news and mobility as crucial elements in contemporary daily news experiences (Jansson and Lindell, 2015; Picone et al., 2015; Schrøder, 2015; Swart et al., 2017), and how emerging practices such as 'clicking', 'liking' and 'scanning', cyclical and brief 'checking' of news, constitute selective 'news repertoires' increasingly integrated into other daily activities (Costera Meijer and Groot Kormelink, 2015; Groot Kormelink and Costera Meijer, 2019); blurring the earlier fixed times of news as well as traditional news geographies (Phillips, 2012). A related area concerns how different digital contexts correlate with distinct forms of news use, with one recent study of young adults' news use, distinguishing between routine surveillance, incidental news exposure and directed consumption (Antunovic et al., 2018). Similarly, the material and sensorial dimensions of digital news consumption - for example regarding the practice of 'scrolling' through the Facebook feed - can be considered as impacting on users' engagement with the news content (Groot Kormelink and Costera Meijer, 2019).

A small number of studies have also started to reconceptualise news from this perspective, but have also worked with a preconceived notion of news as the product of institutional journalism. Swart et al. (2017) provide important rethinking of news in relation to public connection, which however stays on a conceptual level, whereas Armstrong et al. (2015) have challenged traditional news values in a study of news evaluations among audiences. Costera Meijer's and Groot Kormelink's (2015) study of news of consumption show a broadening definition of what counts as news according to news users: as not only events described by journalists, but also everything that is new - from developments in the personal life of one's Facebook friends to opinions on Twitter and information on specific websites. In a comparative study of Estonian and Portuguese news audiences Brites and Kõuts-Klem (2017) explore changing news conceptions in different age groups, showing how traditional news brands held important positions in the audiences' understanding of news, but that young news consumers in both countries were more open for alternative production processes and channels of distribution in interpretations of what it is. In their study of teenage news users in the United States, Clark and Marchi (2017), similarly, use the concept of 'connective journalism' to describe how practices such as sharing or inserting oneself into a story can be fundamental dimensions of young people's news understanding, emphasising the importance of feelings and affective publics ${ }^{4}$ (c.f. Papacharissi, 2015).

Such work opens up for further enquiry into the category of news itself. In order to understand this more broadly, we mean it is important to move beyond the affective dimensions of news practices, aiming at not only the feelings of news consumption, but also its meaning anchored in everyday practice. In the following, we therefore suggest that a phenomenological perspective might be fruitful when exploring how audiences in digital culture understand news. 


\section{Towards a phenomenology of news}

In order to build on other researchers' empirical attempts to understand news in everyday life, we must however tackle the paradox that comes with leaving a prefixed definition of news. Frankly, if news is in a state of flux, how do we get a grip of it? The attempt to uncover present understandings of news, thus, addresses an epistemological dilemma: how can we understand that which we do not know what it is? How can we study news if we leave agreed-upon news understandings behind, if we are to 'bracket' the way we have been thinking about news for decades, even centuries? Here, Peters (2012) mean we need to study news practices in their cultural context since 'if we want to understand the meaning audiences make from news, studies of content must be augmented by a focus on "flow" (the conversation and uses of news by audiences)' (p. 702). Swart et al. (2016) similarly, stress the importance of a user-oriented standpoint and for paying attention to the ways news are embedded within people's everyday lives (p. 3, also Maxwell Hamilton and Tworek, 2017: 392; Peters and Schrøder, 2018; Picone et al., 2015).

Against the backdrop of such considerations, phenomenology can be described as a way to approach the world and the phenomena within it with 'wonder' - an approach that 'creates an openness to the world and a wondering attentiveness' (Van Manen, 2016: 36) that is useful when exploring news from the audiences' own point of view. Such a perspective means 'bracketing' our already learnt understanding of the world and the phenomena in it, and approach them in a new, clear way. We suggest approaching news from such as blank position (as far as possible), but through the experiences of media audiences, in order to challenge the way news is generally understood within news research. 'Bracketing' our understanding of news hence means leaving the traditional understanding of news as a commodity produced and packaged within organised journalistic institutions - including a fixed understanding of its fundamental dimensions; newness, truth-claim, tone, values and actors determining what is newsworthy (e.g. Galtung and Ruge, 1965; Gans, 1979; Tuchman, 1978). In this we follow Deuze's and Witschge's $(2018,2020)$ approach to go 'beyond' journalism, as we also propose going 'beyond' the dominating contemporary Anglo-American understanding of what news is (also Maxwell Hamilton and Tworek, 2017), an approach particularly important in our study that includes empirical work in Western Europe as well as in postSoviet states.

Alongside 'bracketing' as a central tenet, phenomenology takes human existence as its vantage point and explores how human subjects exist and create meaning in their everyday lives in relation to basic categories such as time, space and sociocultural relevance. Heidegger's (2010 [1927]) theoretical notion of 'Dasein', or 'being in the world' is grounded in the understanding of human existence as co-existent with the surrounding world and intentional. This intentionality makes the being of humans temporal in its futurity, that is, it is directed to the projects and goals towards which it strives. Dasein is neither fundamentally free, nor fundamentally determined by its context, and comports itself in the activities it choses to engage in everyday life (Heidegger, 1996). Dasein is also related to an individual's lifeworld; the subjective world of an individual, as it is perceived through his or her eyes (and other senses). News perceptions and 
practices are also part of this intentionality, as news users use and value news depending on what they find relevant (c.f. Pentina and Tarafdar, 2014). But news is not only temporally organised, nor is human's broader existence in the world. Maurice MerleauPonty (1962) has enriched Heidegger's predominantly temporal phenomenology by arguing our existence is also spatially relational, as a 'form of perception' (p. $281 \mathrm{ff}$.). The spatial dimensions of phenomenology have been intensely discussed and developed within media research. ${ }^{5}$ Merleau-Ponty studied the embodiment of human existence, which led him to suggest that our notions of time and space must be understood in relation to our bodily consciousness, as part of human practice. Digital media have profoundly altered how humans experience space, both from a general perspective (Meyrowitz, 1986; Moores, 2012; etc.), and in relation to news (Peters, 2012; Van Damme et al., 2015). To understand how media users perceive news, we must thus anchor our understanding in their temporal and spatial directedness, their intentionality, grounded in their everyday life practices and the specific cultural and material context of news consumption, obviously shifting both between and within countries and media landscapes.

A phenomenological perspective, further, brings attention to how the basic dimensions of the lifeworld coincide with the basic dimensions of not only news consumption, but also of news values; time, space and (sociocultural) relevance (Van Damme et al., 2015; see also Costera Meijer and Groot Kormelink, 2015; Dimmick et al., 2011). This opens up for further enquiry relating not least to digital news, as the ways digital news is produced and distributed have consequences for how news consumers experience themselves, the world, and their own position in it. In relation to space, Peters (2012) argues 'space matters for how we experience journalism and that how we experience journalism shapes our social spaces’ (p. 701, also Schrøder, 2015: 74), suggesting that space has a particular phenomenological meaning for digital news consumption, as:

the emerging technologies and increasingly mobile spatialities of journalism do more than just replicate news content - by changing the public's experience of journalistic consumption, they change what news is. (p. 701)

In addition, Keightley's and Downey's (2018) exploration of the temporal dimensions of news consumption is worth highlighting, showing that the interplay between mediated and socially constructed time in news consumption demonstrate a natural embrace of the multiple temporalities in everyday experience, and that 'zones of intermediacy' in news consumption not only emphasise speed, but also the various constellations of time in which individuals connect with social, cultural, historical and technological temporalities. Peters and Schrøder (2018), similarly, argue that the complex news consumption patterns following from the shifting media repertoires of digital cultures 'demands a more dynamic starting point around how temporality is conceived' (p. 1086).

These important attempts to address the temporality and spatiality of digital news consumption, then, point towards their relevance in a phenomenological approach to news, underlining the importance of anchoring our understanding of media users' perceptions of news in their temporal and spatial directedness, and its relevance in everyday practice. 


\section{News from below: A 'post-phenomenological' approach}

When trying to develop a methodological approach based on the theoretical perspective outlined earlier, we have already mentioned 'bracketing' as a common tenet of a phenomenological understanding, meaning we need to put brackets around the well-known and taken for granted regarding what news is, in order to fully understand what news means to audiences today. Bracketing is part of what Husserl (1931) called 'phenomenological reduction' (pp. 44-49), which is when the philosopher brackets her natural belief of the world, and her common sense assumptions (Van Manen, 2016: 27). Here, we are however not interested in the phenomena as such, their being in the world (c.f. Scannell, 2014), but rather to understand news through the eyes of others; of young media users. We thus suggest we look to what Don Ihde $(1993,2003)$ calls a 'post-phenomenological' approach and Van Manen (2016) conceptualise as 'practical lifeworld studies' (p. 23), which direct the phenomenological analysis towards practices and perception of others. We also adhere to a 'critical phenomenology' underscoring the 'political and socioeconomic determinants of life and peoples' living conditions (Van Manen, 2016: 95; c.f. also Couldry's and Hepp's, 2017, call for a 'materialist phenomenology') in order to meet the critique against phenomenological research for lacking a critical perspective (Desjarlais and Throop, 2011: 93), this means taking into account the economic and political frames of news, variations in content, algorithmic curation and technological gatekeeping,and so on, that both not only frame everyday news practices but also challenge decisionmaking and intentionality among news audiences in today's 'algorithmic cultures' (c.f. Seyfert and Roberge, 2016; Striphas, 2015).

As mentioned earlier, we are currently developing such an approach within a research project looking at news understandings among young adults in three different countries Estonia, Russia and Sweden - where the intention is to use several qualitative methods, including focus groups, in-depth interviews and elements of participant observation and 'think-aloud' protocols, in order to gain a nuanced understanding of young user's news perceptions and practices in these countries. Carrying out a cross-cultural study can be one way of highlighting how news consumption co-exist with the material and political economical conditions of the surrounding world, even if it also entails methodological and analytical challenges. One overarching challenge, however, for empirical research on news audiences picking up on the approach outlined here, is the question of how audiences themselves will be able to bracket the traditional notion of news, and how this can be approached methodologically using a 'phenomenological toolbox', in concrete research practice.

In our own empirical work, we have found inspiration in earlier studies that have approached media use from a phenomenological perspective, such as Maria Bakardjieva's (2005) ground-breaking Internet Society, in which she studied Internet adoption among ordinary Canadians and Bent Steeg Larsen's study of radio users in 1990s Denmark where he, for example, theorised the distinction between 'listening to' and 'hearing' the radio (see also Groot Kormelink and Costera Meijer, 2019; Moores, 2012; Pink, 2011, etc.). These differences in intentionality among the radio listeners reveal the meaning of the radio in the audiences' everyday life, and more specifically how it is meaningful in the users' transformation from the inner (home) to the outer (public space) world and how they orient themselves in time (also Bengtsson, 2006). 


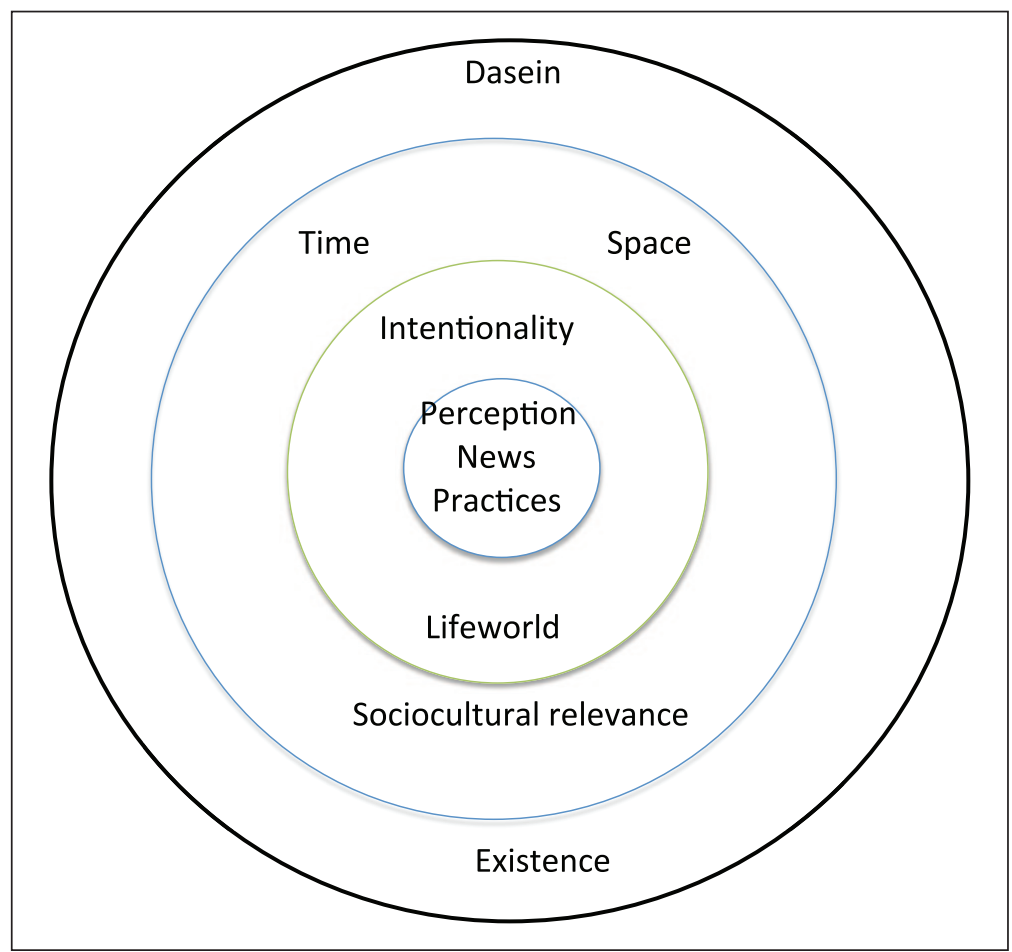

Figure I. A phenomenology of news: model of analysis.

Building on their, and others' work, we suggest approaching news with a phenomenological toolbox based on the concepts of space, time and sociocultural relevance (Schutz and Luckman, 1973), being fundamental dimensions of the lifeworld (as well as of news). In contrast with Bakardjieva, Steeg Larsen and others, however, we cannot take our empirical material for granted, as it is neither a fixed media technology, a preconceived content or specific kinds of topic that we are aiming at (but what we are trying to understand).

We have taken the basic dimensions of 'Dasein', or 'being in the world' as vantage point for our approach towards young media users' perceptions and practices of news, constructed through the temporal, spatial and sociocultural dimensions of it. As we believe it is important to look at on the one hand news perceptions (the audiences' ideas of what news is), and on the other hand at news as part of everyday routines and practices, we will look at how the audiences conceptualise news in relation to, for them, vital information (actively, as part of their intentionality), as well as the more routinized practices where news is part of a flow that we can either just walk through (c.f. 'hear' in Steeg Larsen's analysis) or actively focus upon (c.f. 'listen' in Steeg Larsen's analysis). Below, we will wrap this methodological approach up in a basic model of analysis (see Figure 1 below). This model puts the perception and practices of news at the centre of the analysis, and approaches it through the temporal and spatial dimensions of the young adults' 'being in the world', intentionality and lifeworld. 
A model is always a reduction, which aims to clarify a set of complex dimensions and relations, and hence, for obvious reasons, reduces complexity. In this model, we have put together the basic dimensions in our attempt to capture news from the audiences' perspective. In the following, we will explain how these concepts can be used in empirical practice.

Having used a phenomenological lens to pin-point time, space and sociocultural relevance as fundamental categories of interest when examining the meaning of news, and relating them to perceptions and practices in everyday life, we would like to end this discussion by briefly exploring how these theoretical concepts can be used in empirical analysis. How do we translate these theoretical concepts into a meaningful methodological approach to study news from the audiences' perspective? In our recently started empirical work, we have used some of the basic phenomenological concepts as our starting points; bracketing, Dasein (or 'being-in-the-world'), intentionality, and lifeworld. In the following, we will suggest an outline for a phenomenological approach to the practice and perception of news.

As already noted, 'bracketing' can be seen as both a theoretical approach and a methodology. On the one hand, it means that we should try to bracket our preconceived understanding of news (in this case), and hence, try not to force our respondents in any particular direction in our empirical work. This, however, also means that we need our respondents to bracket their predetermined understanding of what news is; a difficult task, to say the least. This way of approaching news does not restrict it to a particular sender, production process or form of distribution, but leaves these categories open to empirical examination. What meanings media audiences fill the concept of news with is what the empirical analysis will explore. We suggest that in order to study news without implying a traditional conception, news must be studied without it being directly mentioned; we must study news without (initially) talking about it. Such a mode of conduct may however encompass a risk that we just end up with an empirical material that contains information about just anything that young adults do with digital (and analogue) media. As a starting point for this we have, however, not mentioned the word news when we introduced the focus of our discussions with the respondents, but instead framed them around young adults' media use in everyday life, what kind of content young adults find important, and why, and so on. Somewhere in the middle of these discussions, in those cases where the concept ('news') was not brought up naturally by the respondents (which it often was), we have gently introduced the concept to the respondents towards the end of the discussions, and in relation to topics that had already been discussed, thus attempting as much as possible to be sensitive to their interpretations.

We use the concept of Dasein, or 'being in the world' as a reminder that our understanding of users' perception and practice of news must be grounded in their individual backgrounds, their experienced position in the world, as the fundamental dimensions of human existence affect how people relate to the world, including (a broad concept of) news. In our empirical work, we, hence, have started our empirical enquiries (interviews, group interviews, field work, etc.) with broad, existential questions such as 'Where are you now?', 'What is important to you, in your life?'. With these questions, we aim to open up for the respondents' lifeworld, to the important dimensions in their lives and how they perceive their position in the world. 
Following Heidegger, we have learnt that Dasein is not stuck in the world where it lives, but has an inherent intentionality; an agency to decide in what direction it wants to walk. This in an obvious way relates to the individual's possibilities in today's multifaceted media landscape; to choose which sources of information to turn to, which topics to engage in, and so on. More profoundly, however, we have taken into account also the subjects' overarching intentionality, starting out our interviews with, again, broad questions such as 'What do you hope for in the future?', 'Where can/do you see yourself in 5 or 10 years?', 'What are your expectations of life?'. The answers to such questions obviously differ a lot according to general sociological variables such as gender, class and education, but even more so comparing young adults in countries as different as Estonia, Russia and Sweden. Intentionality relates to more than mere interest, it also aims at capturing one's hopes, wishes and ideas of what is meaningful and important in the world. As already mentioned earlier, intentionality also emphasises, in a more down-to-earthway, the agency of news users; how they in the current digital media landscape need to, in a more focussed way than news users did before, select among a great variety of information and news (in a broad sense) that flow over them in both social networking media and other media channels (they, hence, need to either 'listen' or to 'hear').

With such a broad perspective, we also aim at nailing down the respondents lifeworld; how they perceive the everyday world around them, what it revolves around and its limitations, due to previous experiences and expectations - also aiming at understanding the structure of relevance that steers their intentionality.

In order to translate this initial understanding of the respondents' existence, intentionality and lifeworld, we have used two different methodological approaches, leaning on two different epistemologies: agency versus practice, intentions versus routines. This methodological approach relates to two different (but related) strands in phenomenology; first, the existentialist phenomenological approach to meaning (c.f. Heidegger) and second, Merleau-Ponty's practice-oriented phenomenology. To fully make use of the phenomenological perspective, we believe it is important to relate to both these perspectives to understand the respondents' perceptions of news, and news practices. This is also a way to make use of different understandings of news as, on the one hand, a way to maintain public connection (c.f. Couldry et al., 2007; Swart et al. 2017) and on the other hand, an everyday practice.

The first methodological approach starts out in intentionality (life orientation and interest) and then directs itself to everyday practice. Here, we continue our interviews, after the initial existential questions, by asking 'which questions matter the most to you in the world?' and 'what topics do you pay attention to in everyday life?'. This approach brings up not only issues such as the environment, economy, the labour market and corruption, but also friends, family and so on, addressing both individual and collective dimensions of the respondents' everyday lives. After having established this, we penetrate the more practice-oriented perspective, 'how do you keep informed in relation to these topics, where do you learn about it, what kind of information do you trust?' and so on. The initial focus here is on perception, what 'news' is as information and connection to the world.

The second approach goes the other way around: from everyday practices to interest (intentionality). Here, we initially focus on what people do with the (digital) media, 
starting out in the broad 'a day in a life' question: 'tell me about your media use an ordinary day (start in the morning, etc.)?'. This broad introduction is followed up by questions such as 'what do you do, and why, why is this important to you (content wise, topic wise, connection to a social group or the wider public, etc.)'. Here, the initial focus is on practices; news as a daily habit.

These two epistemological approaches both aim at deeper penetrating the respondents' perceptions of news and how they are practised, and are both anchored in a broader idea of meaning. The two different starting points for our discussions with the respondents however opens up for two different ways of understanding news; both of utmost importance for our understanding of what news means to young audiences today. Using two different approaches to the audiences' perception and practice of new diminishes the risks of delimiting the way the respondents talk about news and hence to capture the varied ways they conceptualise news. These approaches to news require us to be sensitive to both conceptual constructions of news in various social contexts and situations, as well as how news practices in these contexts and situations construct what news is. The discussions also focus the temporal and spatial dimension of news (from the audiences' perspective), including the basic aspect of newness and the variations in understandings of this, its (various kinds of) speed and urgency, as well as slowness and repetition in digital news consumption. The spatial dimensions of news perceptions and practices include dimensions both of the location of news consumption and the increasingly mobile spatialities of journalism' (Peters, 2012: 701), but also the opening up of the world by digital media (c.f. Moores, 2012) and how that relates to geographical as well as cultural proximity, and the construction of relevance by it. All these dimensions (and more) are used to explore the perceptions and practices of news. Our interviews in one way or another seem to so far always end up in discussions about the traditional notion of news. But how these discussions are carried out, and what they revolve around vary according to what the respondents have brought up earlier in the discussions.

\section{Concluding notes}

In this article, we have addressed one of the most difficult and important questions for contemporary democracy; how people in digital culture perceive and practice news. In line with several other scholars, we believe turning to news consumption and ordinary news users to be the most fruitful way to approach this, with an eye on the mundane contexts of daily life. We have in this article proposed using a phenomenological approach to find an answer to this truly elusive question, and in line with this argues for 'bracketing' our preconceived understanding of news, in our broader search for it. We also need to anchor our understanding of how people perceive and practice news, in their 'being-in-the-world', that is, what is meaningful to them. In line with phenomenological theory, as well as much news research, we argue that the most fundamental dimensions of peoples' exploration of the world, as well as their understanding of news, coincide and suggest we take these dimensions - of time, space and sociocultural relevance - as vantage points for approaching news perceptions and practices in everyday life. Such a perspective holds the potential to renewing news research, and thereby contributing to nuancing scholarly understanding of news in digital culture. 


\section{Funding}

The author(s) disclosed receipt of the following financial support for the research, authorship, and/ or publication of this article: The research project that frames this article is funded by The Foundation for Baltic and East European Studies.

\section{ORCID iD}

Stina Bengtsson (iD https://orcid.org/0000-0001-6903-141X

\section{Notes}

1. Some scholars of journalism history have advanced a similar perspective. See for instance, Martin Conboy's (2002) analysis of the history of popular journalism.

2. Related fields of investigation have concerned, for example, how offline and online news consumption may differ or be complementary in stimulating political knowledge, as well as societal consequences of fragmentising news audiences as a result of digitisation (Mitchelstein and Boczkowski, 2010), with 'news-avoidance' a particular concern (e.g. Aalberg et al., 2013; Kruikemeier and Shehata, 2016; Ksiazek et al., 2010; Shehata and Wadbring, 2012; Strömbäck et al., 2013).

3. See, for example, Almgren and Olsson (2015); Hermida et al. (2012); Karlsson et al. (2015); Kleis Nielsen and Schrøder (2014); Larsson (2016); Örnebring (2008); Picone (2011); Purcell et al. (2010); Thorsen and Allen (2014).

4. Clarc and Marchi's empirical focus is on disenfranchised, minority and migrant teenagers, which means their discussion relates to a specific group of young people.

5. c.f. Scannell (2014); Bakardjieva (2005); Bengtsson (2018); Moores (2012); Pink (2011); Steeg Larsen (2000); Tudor (2018), and so on.

\section{References}

Aalberg T, Blekesaune A and Elvestad E (2013) Media choice and informed democracy: Toward increasing news consumption gaps in Europe? The International Journal of Press/Politics 18(3): 281-303.

Almgren SM and Olsson T (2015) 'Let's get them involved' . . . to some extent: Analyzing online news participation. Social Media + Society 1(2): 1-11.

Almgren SM and Olsson T (2016) Commenting, sharing and tweeting news: Measuring online news participation. Nordicom Review 37(2): 67-81.

Antunovic D, Parsons P and Cooke TR (2018) 'Checking'and googling: Stages of news consumption among young adults. Journalism 19(5): 632-648.

Armstrong CL, McAdams MJ and Cain J (2015) What is news? Audiences may have their own ideas. Atlantic Journal of Communication 23(2): 81-98.

Bakardjieva M (2005) Internet Society: The Internet in Everyday Life. London: SAGE.

Balmas M (2014) When fake news becomes real: Combined exposure to multiple news sources and political attitudes of inefficacy, alienation, and cynicism. Communication Research 41(3): 430-454.

Bausinger H (1984) Media, technology and daily life. Media Culture \& Society 6(4): 343-351.

Bengtsson S (2006) Symbolic spaces of everyday life. Nordicom Review 27(2): 119-132.

Bengtsson S (2018) Sensorial organization as an ethics of space: Digital media in everyday life. Media and Communication 6(2): 39-45.

Bergström A (2008) The reluctant audience: Online participation in the Swedish journalistic context. Westminster Papers in Communication and Culture 5(2): 60-80. 
Bird ES (1992) For Enquiring Minds: A Cultural Study of Supermarket Tabloids. Knoxville, TN: Knoxville University Press.

Bird ES (2000) Audience demands in a murderous market: Tabloidization in US television news. In: Sparks C and Tulloch J (eds) Tabloid Tales: Global Debates Over Media Standards. Oxford: Roman \& Littlefield, pp. 213-228.

Bird ES (2011) Seeking the audience for news: Response, news talk, and everyday practices. In: Nightingale V (ed.) Handbook of Audience Studies. New York: Blackwell, pp. 489-508.

Boczkowski PJ and Mitchelstein E (2013) The News Gap: When the Information Preferences of the Media and the Public Diverge. Cambridge, MA: MIT Press.

Broersma M and Graham T (2013) Twitter as a news source: How Dutch and British newspapers used tweets in their news coverage, 2007-2011. Journalism Practice 7(4): 446-464.

Clark LS and Marchi R (2017) Young People and the Future of News: Social Media and the Rise of Connective Journalism. Cambridge: Cambridge University Press.

Conboy M (2002) The Press and Popular Culture. London: SAGE.

Costera Meijer I and Groot Kormelink T (2015) Checking, sharing, clicking and linking: Changing patterns of news use between 2004 and 2014. Digital Journalism 3(5): 664-679.

Couldry N and Andreas H (2017) The Mediated Construction of Reality. Cambridge: Polity Press.

Couldry N, Sonia L and Tim M (2007) Houndmills. Basingstoke: Palgrave Macmillan.

Desjarlais R and Throop CJ (2011) Phenomenological approaches in anthropology. Annual Review of Anthropology 40: 87-102.

Deuze M and Witschge T (2018) Beyond journalism: Theorizing the transformation of journalism. Journalism 19(2): 165-181.

Deuze M and Witschge T (2020) Beyond Journalism. Cambridge: Polity Press.

DeVito MA (2016) From editors to algorithms: A values-based approach to understanding story selection in the Facebook news feed. Digital Journalism 5(6): 753-773.

Dimmick J, Feaster JC and Hoplamazian GJ (2011) News in the interstices: The niches of mobile media in space and time. New Media \& Society 13(1): 23-39.

Franklin B, Lewis J and Williams A (2009) Journalism, news sources and public relations. In: Allan S (ed.) The Routledge Companion to News and Journalism. Abingdon; New York: Routledge, pp. 202-212.

Galtung J and Ruge MH (1965) The structure of foreign news: The presentation of the Congo, Cuba and Cyprus crises in four Norwegian newspapers. Journal of Peace Research 2(1): 64-90.

Gans H (1979) Deciding What's News. New York: Pantheon.

Gauntlett D and Hill A (1999) TV Living. London: Routledge.

Groot Kormelink T and Costera Meijer I (2019) Material and sensory dimensions of everyday news use. Media, Culture \& Society 41: 637-653.

Hagen I (1992) News Viewing Ideals and Everyday Practices: The Ambivalence of Watching 'Dagsrevyen'. Bergen: Department of Mass Communication.

Hamilton JM and Tworek HJS (2017) The natural history of the news: An epigenetic study. Journalism 18(4): 391-407.

Heidegger M (1996) Being and Time: A Translation of Sein und Zeit. Albany, NY: SUNY press.

Hermida A (2010) Twittering the news: The emergence of ambient journalism. Journalism Practice 4(3): 297-308.

Hermida A, Fletcher F, Korell D, et al. (2012) Share, like, recommend: Decoding the social media news consumer. Journalism Studies 13(5-6): 815-824.

Husserl E (1931) Ideas: General Introduction to Phenomenology, vol 1 (trans. WRR Gibson). London: George Allen \& Unwin. 
Ihde D (1993) Postphenomenology: Essays in the Postmodern Context. Evanston, IL: Northwestern University Press.

Ihde D (2003) Postphenomenology - Again. Aarhus: Department of Information \& Media Studies.

Jansson A and Lindell J (2015) News media consumption in the transmedia age. Journalism Studies 16(1): 79-96.

Johansson S (2007) Reading Tabloids: Tabloid Newspapers and Their Readers. Huddinge: Södertörn Academic Studies.

Jönsson AM and Örnebring H (2011) User-generated content: Empowerment of citizens or interactive illusion? Journalism Practice 5(2): 127-144.

Karlsson M, Bergström A, Clerwall C, et al. (2015) Participatory journalism - The (r)evolution that wasn't: Content and user behavior in Sweden 2007-2013. Journal of Computer-Mediated Communication 20(3): 295-311.

Keightley E and Downey J (2018) The intermediate time of news consumption. Journalism 19(1): 93-110.

Khaldarova I and Pantti M (2016) Fake news: The narrative battle over the Ukrainian conflict. Journalism Practice 10(7): 891-901.

Kleis Nielsen R and Schrøder KC (2014) The relative importance of social media for accessing, finding, and engaging with news. Digital Journalism 2(4): 472-489.

Kõuts-Klemm R and Brites MJ (2017) Comparison of news consumption on online among Estonian and Portuguese audience Participations. Journal of Audience \& Reception Studies 14(2): 464-483.

Kruikemeier S and Shehata A (2016) News media use and political engagement among adolescents: An analysis of virtuous circles using panel data. Political Communication 34(2): 221-242.

Ksiazek TB, Malthouse EC and Webster JG (2010) News-seekers and avoiders: Exploring patterns of total news consumption across media and the relationship to civic participation. Journal of Broadcasting \& Electronic Media 54(4): 551-568.

Larsen BS (2000) Radio as ritual. Nordicom Review 21(2): 259-274.

Larsson AO (2016) I shared the news today, oh boy: News provision and interaction on Facebook. Journalism Studies 19(1): 43-61.

Lull J (1990) Inside Family Viewing: Ethnographic Research on Television Audiences. London: Routledge.

Madianou M (2013) Living with news: Ethnography and news consumption. In: Stuart Allan (ed) The Routledge Companion to News and Journalism Studies. London: Routledge, pp. 428-438.

Marchi R (2012) With Facebook, blogs, and fake news, teens reject journalistic objectivity. Journal of Communication Inquiry 36(3): 246-262.

Merleau-Ponty M (1962) Phenomenology of Perception [Phénoménologie de la Perception]. London: Routledge \& Kegan Paul.

Meyrowitz J (1986) No Sense of Place: The Impact of Electronic Media on Social Behavior. Oxford: Oxford University Press.

Mitchelstein E and Boczkowski PJ (2010) Online news consumption research: An assessment of past work and an agenda for the future. New Media \& Society 12(7): 1085-1102.

Moores S (2012) Media, Place and Mobility. Basingstoke: Palgrave Macmillan.

Morley D (1980) The Nationwide Audience. London: British Film Institute.

Opermann S (2014) Generational use of news media in Estonia: Media access, spatial orientations and discursive characteristics of the news media. Doctoral Dissertation, Södertörn University, Huddinge. 
Örnebring H (2008) The consumer as producer - Of what? User-generated tabloid content in the Sun (UK) and Aftonbladet (Sweden). Journalism Studies 9(5): 771-785.

Papacharissi Z (2015) Affective Publics: Sentiment, Technology, and Politics. Oxford: Oxford University Press.

Papathanassopoulos S, Coen S, Curran J, et al. (2013) Online threat, but television is still dominant: A comparative study of 11 nations' news consumption. Journalism Practice 7(6): 690-704.

Pentina I and Tarafdar M (2014) From 'information' to 'knowing': Exploring the role of social media in contemporary news consumption. Computers in Human Behavior 35: 211-223.

Peters C (2012) Journalism to go: The changing spaces of news consumption. Journalism Studies 13(5-6): 695-705.

Peters C and Schrøder CK (2018) Beyond the here and now of news audiences: A process-based framework for investigating news repertoires. Journal of Communication 68(6): 1079-1103.

Pettegree A (2014) The Invention of News: How the World Came to Know About Itself. New Haven, CT: Yale University Press.

Phillips A (2012) Sociability, speed and quality in the changing news environment. Journalism Practice 6(5-6): 669-679.

Picone I (2011) Produsage as a form of self-publication: A qualitative study of casual news produsage. New Review of Hypermedia and Multimedia 17(1): 99-120.

Picone I, Courtois C and Paulssen S (2015) When news is everywhere: Understanding participation, cross-mediality and mobility in journalism from a radical user perspective. Journalism Practice 9(1): 35-49.

Pink S (2011) Multimodality, multisensoriality and ethnographic knowing: Social semiotics and the phenomenology of perception. Qualitative Research 11(3): 216-276.

Prior M (2007) Post-broadcast Democracy: How Media Choice Increases Inequality in Political Involvement and Polarizes Elections. New York: Cambridge University Press.

Purcell K, Rainie L, Mitchell A, et al. (2010) Understanding the Participatory News Consumer: How Internet and Cell Phone Users have Turned News into a Social Experience. Pew Research Center, Pew Internet \& American Life Project, and Project for Excellence in Journalism. Available at: https://www.pewresearch.org/internet/2010/03/01/understandingthe-participatory-news-consumer/

Reinemann C, Stanyer J, Scherr S, et al. (2012) Hard and soft news: A review of concepts, operationalizations and key findings. Journalism 13(2): 221-239.

Scannell P (2014) Television and the Meaning of 'Live': An Enquiry into the Human Situation. Cambridge: Polity Press.

Schrøder KC (2015) News media old and new: Fluctuating audiences, news repertoires and locations of consumption. Journalism Studies 16(1): 60-78.

Schutz A and Luckman T (1973) The Structures of the Life World, orig. ca 1950 (trans. RM Zaner and HT Engelhardt). London: Heinemann..

Seyfert R and Roberge J (eds) (2016) Algorithmic Cultures: Essays on Meaning, Performance and New Technologies. London: Routledge.

Shehata A and Wadbring I (2012) Allt fler står utanför nyhetsvärlden. In: Weibull L, Oscarsson H and Bergström A (eds) I framtidens skugga. Göteborg: SOM-institutet, pp. 373-385.

Simons G (2016) The impact of social media and citizen journalism on mainstream Russian news. Russian Journal of Communication 8(1): 33-51.

Striphas T (2015) Algorithmic culture. European Journal of Cultural Studies 18(4-5): 395-412.

Strömbäck J, Djerf-Pierre M and Shehata A (2013) The dynamics of political interest and news media consumption: A longitudinal perspective. International Journal of Public Opinion Research 25(4): 415-435. 
Swart J, Peters C and Broersma M (2016) Navigating cross-media news use. Journalism Studies 18(11): 1343-1362.

Swart J, Peters C and Broersma M (2017) Repositioning news and public connection in everyday life: A user oriented perspective on inclusiveness, engagement, relevance and constructiveness. Media, Culture \& Society 39(6): 902-918.

Thorsen E and Allen S (eds) (2014) Citizen Journalism: Global Perspectives, vol. 1. New York: Peter Lang.

Thurman N, Moeller J, Helberger N et al. (2019) My friends, editors, algorithms, and I: Examining audience attitudes to news selection. Digital Journalism: 1-23.

Tuchman G (1978) Making News: A Study in the Construction of Reality. New York: Peter Lang.

Tudor M (2018) Desire lines: Towards a queer digital media phenomenology. Doctoral Dissertation, Södertörn University, Huddinge.

Van Damme K, Courtois C, Verbrugge K, et al. (2015) What's APPening to news? A mixed-method audience-centred study on mobile news consumption. Mobile Media \& Communication 3(2): 196-213.

Van Manen M (2016) Phenomenology of Practice: Meaning-giving Methods in Phenomenological Research and Writing. London: Routledge.

Wasserman H (2010) Tabloid Journalism in South Africa: True Story! Bloomington, IN: Indiana University Press.

\section{Author biographies}

Stina Bengtsson is professor in Media and Communication at Södertörn University, Stockholm, Sweden. Her main research interests cover media audiences, media practice, meaning, ethics and morality, and how people negotiate and organise the media in everyday life. She is currently engaged in the research project 'What is news? News perceptions and practices among young adults in times of transition'.

Sofia Johansson is Senior Lecturer in Media and Communication at Södertörn University, Stockholm, Sweden. Her research interests cover popular journalism, media audiences, celebrity cultures and how digital technologies shape understandings of sociality and culture more widely. She has published widely on these issues and is currently heading the cross-national research project 'What is news? News perceptions and practices among young adults in times of transition'. 